\title{
Gênero e automutilação na escola básica: um estudo de caso
}

\section{Gender and self-mutilation in primary school: a case study}

\author{
${ }^{1}$ Juliana Soares Dionísio jujuliaquei@gmail.com \\ ${ }^{2}$ Paulo Pires de Queiroz
}

\section{RESUMO}

Em meio ao intenso debate da atualidade sobre gênero e educação, surge a demanda de uma escola de ensino fundamental, situada em uma área de extrema miserabilidade e violência: a automutilação entre adolescentes vítimas de abuso sexual. A despeito desta realidade, o sistema educacional permanece ancorado em uma estrutura 'escolarizatória', que pouco vislumbra os demais aspectos da vida de seu alunado. Com base nesta premissa, este trabalho objetivou analisar as possíveis correlações entre as relações de gênero e episódios de automutilação identificados entre adolescentes que compõem esta comunidade escolar. Para tanto, foram realizadas rodas de conversa semanais, com 10 jovens- com idades entre 11 e 15 anos, além de 3 profissionais da educação. Utilizamos ainda como instrumento metodológico, a observação livre e o registro em caderno de campo. Através da articulação e análise dos dados coletados, observamos que as relações de gênero estariam a funcionar como o arcabouço no qual toda a estrutura de violência se erige. A falta de estrutura e preparo dos espaços e agentes públicos, estaria a fomentar o desenvolvimento do autoflagelamento como alternativa de expurgo das dores psíquicas. Neste cenário, entendemos a necessidade de repensar a educação em gênero e desconstruir paradigmas fundamentados em valores patriarcais hegemônicos.

Palavras-chave: Gênero. Educação em gênero. Automutilação. Escola básica. Violência sexual.

\begin{abstract}
Amid the current intense debate on gender and education, there is a demand for a primary school located in an area of extreme misery and violence: self-mutilation among adolescents who are victims of sexual abuse. In spite of this reality, the educational system remains anchored in a school structure, that little glimpses the other aspects of the life of its pupil. Based on this premise, this study aimed to analyze the possible correlations between gender relations and episodes of self - mutilation identified among adolescents that make up this school community. For that, weekly talk wheels were held, with 10 young people-aged between 11 and 15 years old, as well as 3 education professionals. We also used as a methodological tool, free observation and registration in a field book. Through the articulation and analysis of the collected data, we observed that gender relations would be functioning as the framework in which the entire structure of violence is erected. The lack of structure and preparation of spaces and public agents, would be encouraging the development of self-flagellation as an alternative to purge psychic pain. In this scenario, we understand the need to rethink education in gender and deconstruct paradigms based on hegemonic patriarchal values.
\end{abstract}

Keywords: Gender. Gender education. Self-mutilation. Basic school. Sexual violence.

1 Fundação Oswaldo Cruz

2 Universidade Federal Fluminense e Fundação Oswaldo Cruz- FIOCRUZ 


\section{INTRODUÇÃO}

A automutilação tem sido um dos grandes desafios enfrentados pelas escolas da atualidade e cada vez mais, desperta as atenções do debate acadêmico. Por vezes, o transtorno pode ser considerado como uma possível consequência das relações de gênero violentas, desiguais e excludentes que caracterizam o tecido social (GONÇALVES; SILVA, 2017).

Os papéis sociais atribuídos aos gêneros estão intimamente articulados à dinâmica de violência neste campo. Parker (apud BEAUVOIR, 1970) afirma que homens e mulheres deveriam ser compreendidos como seres humanos, em posição de igualdade. Contudo, podemos perceber a reprodução contínua de um mecanismo patriarcal de construção identitária no qual as identidades femininas tendem a ser definidas a partir de uma identidade masculina hegemônica. Nesse sentido, o patriarcalismo estabelece relação de domínio sobre todos os demais que não se enquadrem na designação do masculino. Neste grupo, estão incluídas crianças, adolescentes, mulheres e homossexuais (DIAS \& CRUZ, 2015). A escola básica se trata de um dos inúmeros espaços sociais onde estas relações se estruturam e solidificam, e indiretamente, acaba por contribuir para o desenvolvimento de comorbidades como a automutilação, depressão e ansiedade. Ao considerar o modo como as relações de gênero estão estabelecidas, podemos refletir sobre o papel desempenhado pela escola no processo de violência produzido a partir deste. Neste aspecto, somos conduzidos a refletir sobre possíveis alternativas que favoreçam o bem-estar físico, mental e social no lócus escolar.

O presente artigo relata o andamento de uma pesquisa resultante da experiência profissional de oito anos de uma agente educadora numa escola municipal do Rio de Janeiro na favela da Pedreira, no bairro Pavuna. Ao longo deste período, foi possível observar e ouvir inúmeros relatos de crianças - sobretudo meninas - que desenvolveram o transtorno da automutilação, após sofrerem abusos sexuais. Com base nestas premissas, nasce a pergunta de partida deste trabalho: de que modo questões de gênero estão relacionadas com o desenvolvimento do transtorno da automutilação entre adolescentes de uma mesma comunidade escolar na favela da Pedreira no Rio de Janeiro? Sob esta perspectiva, a investigação objetivou analisar as possíveis correlações entre as relações de gênero e episódios de automutilação identificados entre adolescentes que compõem essa comunidade escolar.

A pesquisa se apoia em um estudo de caso, utilizando, como instrumentos metodológicos, rodas de conversa, observação livre e registro em caderno de campo. Procura-se desta maneira conhecer possíveis ocorrências de episódios de automutilação, identificar as correlações entre a prática e as relações de gênero e avaliar os resultados obtidos nas dinâmicas empreendidas.

Neste artigo, privilegiaremos uma análise de rodas de conversa desenvolvidas como um desdobramento de um projeto de pesquisa de mestrado da área de ensino. A dinâmica ocorreu em espaços alternativos na comunidade, com uma frequência semanal, por um período de 5 meses_de fevereiro a julho de 2018. Participaram crianças entre 11 e 15 anos - de ambos os gêneros - que desenvolveram o transtorno da automutilação. Atuando como facilitadores do diálogo, estão 3 profissionais com formação na área da educação em correntes holísticas. Todos os facilitadores possuem vivência na área de violência de gênero. Os adolescentes participantes frequentam uma mesma escola no bairro, e de acordo com relatos da comunidade escolar, alguns deles já haviam sofrido violência de gênero.

A utilização da metodologia de rodas de conversa com diferentes atores, tendo por objetivo destacar que o emprego dessa favorece a construção de uma prática dialógica em pesquisa, se legitimou nessa proposta de investigação por possibilitar o exercício de pensar compartilhado. Inicialmente, descreveremos o desenvolvimento das rodas de conversa na tentativa de conhecer o cotidiano dos sujeitos da pesquisa. Nessa pesquisa foi feito uso da observação participante e de algumas rodas de conversas como recursos metodológicos, tendo como respaldo a abordagem da Psicologia Social Discursiva. Nesse sentido, trabalharemos, potencialmente, à descrição das rodas de conversas realizadas, trazendo à tona a contribuição dos autores para pensar essa metodologia participativa, os quais foram Méllo et al. (2007), Afonso e Abade (2008). 
De acordo com Méllo et al. (2007), as rodas de conversa priorizam discussões em torno de uma temática (selecionada de acordo com os objetivos da pesquisa) e, no processo dialógico, as pessoas podem apresentar suas elaborações, mesmo contraditórias, sendo que cada pessoa instiga a outra a falar, sendo possível se posicionar e ouvir o posicionamento do outro. Ao mesmo tempo em que as pessoas falam suas histórias, buscam compreendê-las por meio do exercício de pensar compartilhado, o qual possibilita a significação dos acontecimentos.

Afonso e Abade (2008) destacam que as rodas de conversa são utilizadas nas metodologias participativas, seu referencial teórico parte da articulação de autores da psicologia social, da psicanálise, da educação e seu fundamento metodológico se alicerça nas oficinas de intervenção psicossocial, tendo por objetivo a constituição de um espaço onde seus participantes reflitam acerca do cotidiano, ou seja, de sua relação com o mundo, com o trabalho, com o projeto de vida.

Para que toda essa dinâmica se desenvolvesse, as rodas de conversa foram operacionalizadas em um contexto onde os sujeitos da pesquisa puderam se expressar, buscando superar seus próprios medos e entraves. Para auxiliá-los nesse processo de quebra dos entraves, bem como para facilitar a comunicação e a interação, foi feito o uso de técnicas de dinamização de grupo, sendo utilizados recursos lúdicos objetivando desconstruir e desnaturalizar a insegurança e o medo dos sujeitos da pesquisa. Apesar de enquanto pesquisadores escolhermos uma técnica visando um objetivo, é o grupo de participantes das rodas de conversa que “dá a palavra final”, ou seja, é ele quem vivencia e direciona a técnica para seus objetivos e propósitos. Conforme ressaltam os autores da epistemologia dessa metodologia de pesquisa, as rodas de conversa se diferenciam de outras atividades grupais, como a terapia de grupo, pois, para o desenvolvimento das rodas de conversa, os sujeitos se expressam no grupo, mas não é necessário que sejam revelados seus segredos, muito menos é orientada a invasão de sua intimidade. Desse modo, trabalhamos com a reflexão e o diálogo, construímos as rodas de conversa a partir das questões de pesquisa, do referencial dos autores citados e de todo o planejamento que nos auxiliou na facilitação das discussões, durante o desenvolvimento das rodas de conversa.

Sendo assim, iniciaremos esta análise discorrendo sobre a automutilação e a popularização desta prática entre jovens em idade escolar, correlacionando o fenômeno aos conceitos de gênero e violência simbólica. Discutiremos o papel da escola nos dias atuais, a importância da educação em gênero como questionadora da violência e promotora da igualdade. Por fim, à luz dessas ideias, abordaremos aspectos discutidos nas rodas de conversa, ressaltando o cotidiano do campo onde esta pesquisa se desenvolve, suas especificidades e peculiaridades.

\section{AUTOMUTILAÇÃO, GÊNERO E VIOLÊNCIA SIMBÓLICA}

\section{1 Automutilação}

A automutilação pode ser enquadrada como um comportamento autodestrutivo, que se designa pela ação de ferir a si mesmo, sem a intenção de ocasionar morte (LAYE-GINDHU; SCHONERT-REICHL. HORNE; CSIPKE apud CAVALCANTE, 2014). Comumente está associada a transtornos mentais como depressão, esquizofrenia, transtorno bipolar, transtornos de personalidade em geral, dentre outros, e produz profundo alívio psíquico para o praticante. Normalmente, este alívio está relacionado a sentimentos de culpa, tristeza profunda e incapacidade de lidar com suas emoções.

Há poucos registros de relatos da automutilação na antiguidade, sendo o primeiro episódio datado em 1901, na Inglaterra. Na contemporaneidade, devido à ampla divulgação de figuras públicas que desenvolveram o transtorno, e do forte apelo através de mídias sociais impulsionando jovens ao uso de tal método, a automutilação tornou-se um grande desafio. Nas escolas, é frequente encontrarmos relatos de adolescentes portando objetos cortantes para se auto lesionarem. A comunidade científica tem se debruçado sobre o problema, e hoje, já é possível encontrar inúmeros trabalhos e pesquisas abordando o tema. De acordo com estes estudos, o surgimento do transtorno, se dá entre os 12 e 14 anos, e tende a perdurar por 10 ou 15 anos. Há uma prevalência maior entre as mulheres (GIUST, 2013). 
De acordo com o relato de alguns/mas participantes das rodas de conversa onde esta pesquisa se desenvolveu, a prática funciona como uma forma de alívio das pressões emocionais sofridas por eles/as. Relatam que, diante da impossibilidade de externar seus sentimentos, buscam nesta conduta um modo de fazê-lo. O sangue vertido através dos cortes funciona como um mecanismo pelo qual as dores psíquicas são extravasadas.

"Meu sangue derramado é a minha droga. Bizarra e tóxica para os outros. Para mim, não. É vida. Estou tentando me salvar, ainda que tenha de cortar as próprias cicatrizes se já não houver mais carne ainda não aberta. E um dia terei uma nova pele, um corpo inteiramente recortado por mim.” (BRUM apud FERREIRA, 2016, p. 31)

A forma mais comum de automutilação se caracteriza por cortes infligidos contra o próprio corpo, de forma repetida, podendo ultrapassar a 50 cissuras em um mesmo indivíduo (GIUST, 2013). Na maioria dos casos, o uso de álcool e drogas não está associado ao transtorno. Os ferimentos, sua extensão, são pensados e desejados pelo sujeito, e normalmente ocorrem na parte interna dos braços- próxima aos pulsos- ou na parte externa das coxas. O distúrbio diferencia-se do suicídio, pois neste último, busca-se pôr fim às dores psíquicas, já no primeiro, procura-se um alívio, um abrandamento do sofrimento. Cabe ressaltar, contudo, que a automutilação pode preceder o suicídio, pois em casos de feridas mais profundas, seja por inabilidade na prática ou necessidade da atenuação de dores mais intensas, o comportamento pode desencadear a morte. Podemos citar ainda como mecanismos de automutilação: queimaduras, arranhões, mordidas, pancadas e aprofundamento de ferimentos pré-existentes. As causas são diversas, desde sentimento de rejeição, abandono, depressão, culpa, vergonha, falta de sentido na própria existência, além de violências sofridas ao longo da vida. Após a prática, o indivíduo se sente aliviado, em estado de bem-estar. Este resultado pode perdurar de horas a dias, contudo, há sempre um retorno ao estado de angústia inicial (FAVAZZA apud GIUST, 2013).

Nosso ponto de vista é que, no contexto escolar, muitas vezes a automutilação pode ser correlacionada às relações de gênero e seus impactos nas identidades femininas. Alunas que sofrem violência de gênero podem estar lançando mão da prática em prol de um bem-estar fugaz que, no entanto, prejudica sua saúde emocional, fisiológica e social. Contudo, o bem-estar, considerado numa perspectiva global (ALMEIDA FILHO, 2000; CANGUILHEM, 1992; SCLIAR, 2007) passa por uma construção coletiva democrática, que questione esse quadro e promova relações equânimes e plurais entre mulheres e homens em todas as esferas sociais. No conceito estabelecido em 1946 pela Organização Mundial de Saúde- OMS, designou-se como saúde, o completo bem-estar físico, mental e social e não apenas, a ausência de doença ou incapacidade. O desenvolvimento de uma vida plena, em todos os seus aspectos, era a expressão exata desta formulação (SCLIAR, 2007).

Tendo como parâmetro o conceito da OMS em 1946, entendemos que produzir reflexões e debates sobre o assunto estaria por si só, colaborando para a promoção da saúde coletiva- o que esperamos ser um dos desdobramentos deste trabalho. Entretanto, muitos debates vêm sendo travados no meio científico, argumentando a impossibilidade do desenvolvimento pleno da saúde diante da abrangência do conceito, considerando a incidência de inúmeros fatores externos determinantes para a consecução deste bem-estar. Para além, a noção de saúde e doença adquiriu inúmeras configurações ao longo da história, dificultando um consenso sobre o tema. Influências sociais, econômicas, culturais e políticas foram determinantes na construção do imaginário coletivo sobre o termo 'saúde', e este fato em si, já é suficiente para que o debate sobre o conceito se sustente. Contudo, diante da complexidade e extensão da discussão não nos aprofundaremos nela neste artigo, mas cabe-nos ressaltar, a importância de que o termo 'saúde’ seja pensado de forma holística, de modo a abranger a prevenção de comorbidades, que estão para além do aspecto físico.

\section{2 Gênero e Violência Simbólica}

Na atualidade, muitas discussões têm sido travadas em torno do conceito de gênero. Termos como ideologia e identidade têm ganhado espaço em debates sobre garantia de direitos, de liberdade, igualdade e equidade. Em décadas passadas, alguns campos científicos, como a Sociologia e a Filosofia, já se ocupavam das prerro- 
gativas relacionadas ao tema. Nos anos 60, ao lançar a segunda edição da obra 'O Segundo Sexo: a experiência vivida', a filósofa Simone de Beauvoir coloca em voga temas de grande relevância social como patriarcalismo, alteridade, minorias ideológicas, dentre outros. A frase "Ninguém nasce mulher: torna-se mulher" (BEAUVOIR, 1967, p. 9), converteu-se em um marco nas reflexões sobre o conceito de gênero. Na crítica da autora (BEAUVOIR, 1970), as características biológicas e físicas, típicas do sexo feminino não são determinantes para sua designação neste grupo, mas sim, o papel atribuído na coletividade. A sociedade imbuída de preceitos patriarcais designa parâmetros sobre o que é "aceitável” e "não aceitável” para o papel instituído para a mulher. Aquelas que não se enquadram neste modelo estabelecido socialmente, são excluídas, desrespeitadas e por vezes violadas. O órgão sexual feminino não é o suficiente para designá-las enquanto fêmeas, mas sim, e muito mais, o comportamento preestabelecido socialmente.

Em sua reflexão, Beauvoir (1970) suscita o conceito de alteridade, no qual a figura masculina assume o papel de dominação, do ser essencial, do Um; enquanto ao feminino sobra a função de inessencial, de subserviência, do Outro. A autora afirma:

Ela [a mulher] não é senão o que o homem decide que seja; daí dizer-se o “sexo” para dizer que ela se apresenta diante do macho como um ser sexuado: para ele, a fêmea é sexo, logo ela o é absolutamente. A mulher determina-se e diferencia-se em relação ao homem e não este em relação a ela: a fêmea é o inessencial perante o essencial. O homem é o Sujeito, o Absoluto; ela é o Outro. (BEAUVOIR, 1970, p. 10)

A mulher estaria para o homem, como um objeto de dominação, existindo para o sexo. Seu corpo como instrumento de domínio, 'coisa' a ser empossada. Bourdieu, em sua análise sobre a dominação masculina, contesta a naturalização e a perpetuação destas condições de existência, considerando-as intoleráveis e inaceitáveis. Para ele, a soberania do homem se fundamenta no processo de violência simbólica, suave e invisível às próprias vítimas, que perpassa por gerações através de uma "extraordinariamente ordinária relação social” (BOURDIEU, 2017, p. 12). O poder simbólico exercido nas relações de dominação é aquele que se estabelece na ignorância de sua existência, contando com a cumplicidade insipiente dos que lhe estão sujeitos e dos que o exercem. Nas relações de gênero, o masculino sobrepõe-se ao feminino através desta vinculação imperceptível, o que de acordo com a visão marxista, está a desempenhar uma função política, fazendo com que os interesses de uma classe se justaponham à outra, tornando questões particulares, universais (BOURDIEU, 1989). As relações de classe se configuram, portanto, como o arcabouço onde toda a dinâmica de sujeição de um gênero para com o outro, se constitui.

No relato de uma das adolescentes participante das rodas de conversa, identificamos todo este processo acima descrito. A menina de 15 anos, nos contou que havia sofrido violência sexual aos 10 anos de idade, e que se sentia profundamente responsável pelo acontecimento. O abuso ocorrera por parte do motorista do transporte particular que a conduzia à escola. Ela nos contou que foram necessários alguns anos para que o abuso fosse revelado à mãe. Afirmou que ao fazê-lo, foi responsabilizada pelo episódio. A matriarca enfatizou que a menina fora estuprada, em consequência das roupas que usava. A dinâmica do poder simbólico está aqui especificada. Esta mãe foi levada a reproduzir 'a verdade' que lhe fora imputada desde seu nascimento: mulheres e homens devem desempenhar os papéis sociais que lhes foram atribuídos. Cabe às mulheres a subserviência e a discrição. Já aos homens, o papel de dominação, de poder, de virilidade. As roupas usadas pela menina estariam em contraste com o "apropriado", com o "esperado", portanto qualquer homem exercendo sua "função social de virilidade", poderia tomar-lhe posse do corpo, ainda que este fosse infantil.

Assim como Beauvoir (1970), Bourdieu evocou a construção social dos corpos, ressaltando que através de mecanismos naturalizantes e legitimantes, o masculino se superpõe ao feminino. O conceito de virilidade está diretamente associado com o "vir, virtus, questão de honra, princípio da conservação e do aumento da honra" (BOURDIEU, 2017, p. 25), e relaciona-se com a apropriação do corpo feminino, com a potência sexual_naturalizadas como características que tornam o homem, um "homem real”. Os órgãos sexuais, feminino e masculino, não são enxergados em um mecanismo de complementariedade, mas sim, de modo dicotômico, onde o primeiro 
é visto como vazio, maléfico, nefasto e o inverso do segundo. De acordo com a construção social dos gêneros, o masculino se sobrepõe ao feminino, se apodera dele e o domina. Nesta relação hegemônica, a violência contra o corpo feminino se justifica, já que este último existe a partir daquele, e para seu completo desfrute. A mulher é objetificada, coisificada, a posse de si mesma lhe é negada. Existe para servir e ser possuída pelo outro.

É possível, pois, admitir a existência de um nexo de significado entre o fenômeno da automutilação e as relações de gênero e violência simbólica. Muitas mulheres tendem a utilizar a prática de forma a aliviar sofrimentos impostos e legitimados por um imaginário social ainda significativamente patriarcal. Diante do exposto, procuraremos entender a seguir os papeis da escola nesta dinâmica de poder.

\section{3 Educação, Gênero e Automutilação: O papel da escola}

A sociedade capitalista, para atender aos interesses da classe dominante, estabelece e normatiza comportamentos para os sexos. Ela dita o que seria “apropriado” para homens e mulheres e se utiliza de instituições como igreja, escola, família para alcançar seu propósito. Esta normatização nos pareceu evidente ao ouvirmos o relato de uma participante da comunidade escolar, que citou a constante reclamação com relação ao uso de maquiagem- particularmente o batom de cor vermelha- por parte da antiga direção da escola- substituída no início do ano de 2018, através de processo eleitoral. Na ocasião, a funcionária afirmou que a queixa fora feita em reuniões de pais e responsáveis, e que a gestão da unidade utilizou palavras de calão para designar as meninas que faziam uso de tal pintura. Homens e mulheres são educados para desempenharem papéis específicos em nossa sociedade, e esta polidez é iniciada desde a mais tenra infância. Na construção da feminilidade, espera-se a adoção de uma postura dócil, subserviente e discreta, e o uso do batom vermelho no caso relatado, estaria sendo enxergado como uma atitude transgressora, extravagante, “chamativa” e, portanto, completamente inapropriada à regra social, tornando-se digna de rechaço, de ser repelida.

Na sociologia da educação, diversos autores refletem sobre os processos de manutenção do poder e reprodução das desigualdades sociais através da escola. Esta, deveria existir como um mecanismo de emancipação do indivíduo, possibilitando sua ascensão social e intelectual. Entretanto, através de um sistema complexo de exclusão, as classes privilegiadas perpetuam seu domínio, utilizando-se também das relações de gênero, como modo de estabelecer a hegemonia do masculino, através da vinculação imperceptível no processo de violência simbólica solidificado pelo sistema escolar e demais instituições sociais. Conforme Louro (2008, p. 20):

A voz que ali se fizera ouvir, até então, havia sido a do homem branco heterossexual. Ao longo da história, essa voz falara de um modo quase incontestável. Construíra representações sociais que tiveram importantes efeitos de verdade sobre todos os demais.

Entretanto, apesar de sua utilização como instrumento de aprisionamento e 'docilização', a escola preserva ainda, sua capacidade de resistência. Ao evocarmos teorias como a educação multicultural, fornecemos o aporte para que esta "nova” escola seja estruturada. Pensar uma educação multicultural é pensar uma escola onde as diferenças não apenas coexistem, mas onde são necessárias para a construção de espaços de inclusão. Esta escola, objetiva fortalecer a comunidade, oportunizando a exploração das diferenças, de modo que a diversidade do cotidiano escolar se desenvolva de forma segura e protegida. Alunos e alunas devem encontrar um espaço propício para o reconhecimento e aceitação das diferenças, de modo a contribuir com a desconstrução de arquétipos, e com a interação e compreensão das especificidades do sexo oposto (QUEIROZ, 2018). Na multiculturalidade, o valor máximo a ser pensado é o da igualdade. Todos e todas possuem os mesmos direitos e se reconhecem enquanto cidadãos e cidadãs. As diferenças são a base para a construção da escola inclusiva, que $a$ posteriori, contribuirá para a formação de um corpo social mais equânime e cooperativo.

A escola deve ser enxergada de modo distinto, como um mecanismo conscientizador de seus agentes - alunos, professores, comunidade escolar - para a construção de uma sociedade distinta e mais igualitária, possibilitando uma real transformação na vida de todos. A questão está para além do êxito escolar do aluno, 
mas se trata de uma intervenção no mundo, e principalmente, da participação do coletivo na elaboração de uma realidade equânime, onde todos e todas possam ser respeitados e respeitadas em suas diferenças, contribuindo assim com a edificação de uma sociedade onde a diversidade torne-se mais a norma do que a exceção (QUEIROZ, 2018).

Ao invés de ser mais uma agência de reprodução social, a escola poderia e deveria assumir um papel democrático que contribua a relações de gênero mais igualitárias e plurais. As rodas de conversa foram desenvolvidas sob tal pressuposto, alavancando importantes achados preliminares para a investigação.

\section{4 Rodas de conversa: conhecendo o cotidiano dos membros do grupo}

As rodas de conversa ocorreram em espaços alternativos na comunidade da Pedreira, na Pavuna, no Rio de Janeiro, com uma frequência semanal, por um período de 5 meses_de fevereiro a julho de 2018. Participaram crianças entre 11 e 15 anos_de ambos os gêneros_que desenvolveram o transtorno da automutilação. Atuando como facilitadores do diálogo, estão 3 profissionais com formação na área da educação em correntes holísticas. Todos possuem vivência na área de violência de gênero. Os adolescentes participantes frequentam uma mesma escola no bairro, e de acordo com relatos da comunidade escolar, alguns deles já haviam sofrido violência de gênero.

No início do ano letivo de 2018, recebemos diversos relatos de membros da comunidade escolar, que davam conta de alunos/as se automutilando dentro de uma escola na comunidade da Pedreira. Em conversas informais, tivemos acesso à informação de que o comportamento autodestrutivo era comum aos alunos, e havia se iniciado tempos atrás. No ano anterior, a antiga direção da escola havia relatado o problema aos pais, que participaram de uma reunião com profissionais da secretaria de saúde, onde foram sensibilizados e informados sobre o assunto, contudo, nenhum trabalho foi desenvolvido posteriormente com o grupo. Os profissionais da saúde que estiveram na escola informaram que a impossibilidade de continuidade no trabalho era devida à falta de pessoal capacitado que pudessem atender a demanda da área, já que dispunham apenas de 2 psicólogos- em turnos de 20 horas semanais- para o atendimento de uma vasta região. Alguns professores relataram que ao conversarem com parte dos alunos envolvidos na prática, descobriram que a situação ocorria como busca de alívio para dores emocionais ocasionadas, em sua maioria, por violências sexuais sofridas no passado e no presente. Iniciamos assim, o trabalho das rodas de conversa, que para além do vínculo com o projeto de pesquisa supracitado, nasceu como um auxílio para às demandas da escola. O objetivo principal das rodas era dar voz aos silenciados. Permitir que as crianças se expressassem e expusessem sua dor, de modo a não mais recorrerem à automutilação como forma de alívio. As rodas de conversa, como instrumento metodológico, para além da captação de dados, possibilitam que os participantes produzam e ressignifiquem saberes, contribuindo para a construção de uma educação voltada para a vida e para a cidadania. Nelas, o conhecimento é construído coletivamente, contribuindo para uma percepção de mundo que considere o olhar do outro e não apenas o individual, possibilitando a interação, além do desenvolvimento de sentimentos de empatia e solidariedade. Desse modo, as rodas de conversa propulsionam a reflexão crítica da realidade, agindo como mecanismo de mudança do tecido social, contribuindo para a construção de uma educação emancipatória (SAMPAIO; SANTOS; AGOSTINI; SALVADOR, 2014).

Já na primeira reunião, pudemos identificar que apenas umas das crianças participantes, não havia sofrido violência sexual. Um caso em particular nos chamou a atenção: de uma criança de 13 anos, que daremos o nome fictício de Emma. Ela, de todas as outras participantes da roda, era a única que ainda sofria abuso. Emma relatou que havia sido violentada por três homens em momentos distintos da vida, e que o último abuso havia ocorrido no mês anterior. A primeira violência havia ocorrido aos 3 anos de idade, às demais, aos 7 e aos 13. De acordo com o relato da adolescente, foram diversos abusos. Os estupradores eram amigos de parentes, que possuíam acesso à casa da família, e a menina. Na terceira semana de reunião, percebemos que Emma estava com hematomas na testa, e ao questionarmos o que havia ocorrido, seu melhor amigo, que aqui denominaremos de Jullian- 
criança que também se automutilava, pois havia desenvolvido uma relação de co-dependência ${ }^{3}$ com Emma, e se cortava em solidariedade à dor da amiga- nos informou que mais uma vez o abuso havia ocorrido. Ele contou que Emma havia ingerido calmantes na tentativa de acabar com a própria vida, após abuso. Neste ínterim, acabou desmaiando e chocando a testa contra o chão. Os pais não estavam em casa quando o fato ocorreu. À noite, ao questionarem a menina sobre os hematomas, Emma lhes disse que havia sofrido uma queda.

Ninguém sabia sobre os abusos. As primeiras pessoas a tomarem ciência da violência foram uma professora e uma funcionária da escola, que atuavam também como mediadoras nas rodas de conversa. Bourdieu ressalta (2017), que na construção de uma sociologia política sobre o ato sexual, homens e mulheres foram preparados para viver sua sexualidade de maneiras bem distintas. Enquanto elas foram educadas para criar expectativas de afetividade e intimidade em uma relação sexual, eles a concebem como um ato agressivo, de dominação. $\mathrm{O}$ ato sexual se apresenta desta forma, porque fora construído no imaginário social, apoiado na divisão entre masculino e feminino. Enquanto o primeiro domina, apropria-se, o segundo, submete-se, subordina-se. A estrutura social incide diretamente sobre a vida individual, e no caso da violência sexual, as relações de poder e dominação criam o cenário propício para que o abuso se desenvolva. Para além de distúrbios psiquiátricos, psicológicos e neurológicos, a formação dos sujeitos pautada em valores patriarcais- que tendem a coisificar os corpos considerados mais frágeis- é o sustentáculo onde toda esta estrutura de violência se erige. Se apoderar, assenhorar-se do outro, acaba por se tornar uma expressão da hegemonia masculina em uma cultura patriarcal, enquanto que, se tornar posse, vergar-se e silenciar, tonam-se características desta feminilidade construída socialmente.

O caso de Emma foi levado à atual direção da unidade escolar que, de acordo com o relato dos mediadores, conseguiu tratamento psicológico gratuito para a menina em uma clínica particular, com o consentimento dos pais. Nas sessões de terapia, a situação foi relatada aos progenitores e o ciclo de violência teve um fim. A família não teve mais nenhuma notícia dos abusadores, e decidiu por não efetivar denúncia na delegacia. Apenas a gestão da escola procedeu uma queixa no conselho tutelar da área. Emma permanece nas rodas de conversa e continua sendo acompanhada por psicólogos na referida clínica. De acordo com o relato de integrantes da comunidade escolar, a menina tem apresentado melhora significativa no comportamento tanto na escola, quanto em casa, participando de brincadeiras com outros alunos, demonstrando afeto para com os colegas, professores, funcionários e familiares- coisas até então inéditas para ela. Emma era uma criança introvertida, deprimida, com sérias dificuldades de contato físico- abraços, beijos no rosto e toque nas mãos.

Outro relato que se destaca é o de um menino de 14 anos, homossexual, que chamaremos de Piter, nesta narrativa. Este adolescente namorava um traficante da área e nos contou que era considerado e tratado como mulher pelos demais criminosos da favela. Estes, se referiam a ele pelo pronome 'ela', e o obrigavam a estar em espaços destinados às esposas dos bandidos, em festas e bailes. O adolescente afirmou que se incomodava profundamente com este tratamento, pois se considerava homem. Bourdieu ressalta (2017), que em algumas sociedades, a posse homossexual é encarada como ato de dominação, de poder, e a afirmação desta superioridade se dá no processo de "feminização” do outro. O ‘feminilizar' estaria associado à humilhação sexual, à fragilidade e à falta de virilidade.

Piter nos contou que certo dia, durante um baile funk, o ‘dono’4 da favela o conduziu até sua casa e o violentou sexualmente. O menino tentou resistir e foi espancado. A mãe do traficante, ao ouvir os gritos, adentrou na casa e retirou o adolescente. Piter nos disse que desde este dia passou a receber ameaças. Caso a história viesse à tona, ele e sua família poderiam sofrer retaliações. O criminoso foi morto alguns meses após o episódio, em um confronto com a polícia. $\mathrm{O}$ adolescente pediu para frequentar as rodas de conversa, pois estava com problemas para dormir, além do pânico em se locomover pela comunidade, mesmo após a morte do bandido. Piter foi encaminhado para o posto de saúde da localidade para acompanhamento com psicólogo e para realização de exames

3 Dependência patológica física ou psicológica com pessoas com problemas como vícios e/ou comportamentos autodestrutivos.

4 Termo utilizado pelos moradores de comunidades para designar o traficante-chefe, aquele responsável pelo comando do tráfico de drogas no local. 
relacionados à detecção de doenças sexualmente transmissíveis. A denúncia às autoridades competentes não foi realizada, nem incentivada, devido ao alto risco que o procedimento poderia ocasionar ao menino e sua família, mesmo após a morte do traficante. De acordo com relatos da comunidade escolar, Piter apresenta melhoras significativas no comportamento e já consegue circular pela comunidade. Ele segue no tratamento com psicólogo e participando das rodas de conversa.

Os casos apresentados são apenas alguns de outros tantos, onde a automutilação está associada com a violência sexual. Os sentimentos de culpa, vergonha, tristeza profunda e desvalorização que acompanham as vítimas, também estão associados ao transtorno, como já explicitado. Neste aspecto, as questões de gênero aparecem como arcabouço de sustentação onde a estrutura última da automutilação se erige. Ao abordarmos igualdade de gênero em quaisquer instituições, sejam escolas, empresas, comunidades, estamos promovendo equidade e respeito entre os sexos, o que é de fundamental importância na prevenção da violência em qualquer instância.

Muito se tem discutido sobre gênero e ideologia de gênero, na atualidade. O que observamos, é que conceitos equivocados têm se difundido na sociedade, proporcionando um prejuízo significativo para o debate. Definições sem qualquer fundamento teórico têm sido disseminadas por inúmeros agentes políticos, impedindo que um dos principais pontos do debate ganhe a proporção devida: a questão da violência. Educação em gênero, a despeito da crença da maioria da população, ocorre todos os dias em escolas, casas e todos os demais espaços sociais. Quando determinamos o que é adequado para mulheres e homens, desde comportamentos à vestimenta, estamos educando em gênero. Ao nos deparamos com as cotidianas notícias, em jornais escritos e televisionados, sobre estupro, espancamento e morte de mulheres, crianças e homossexuais, entendemos o quão equivocada é a educação em gênero que nossa sociedade está recebendo há séculos. Abrir escolas e instituições para este debate, só contribui para que possamos refletir sobre nossos desacertos. Fomentar uma educação multicultural, que valorize e acolha as diferenças entre os gêneros, nos possibilita esta reflexão. Promover o princípio da igualdade em nossos espaços sociais, nos garantirá equidade de oportunidades e prevenção da violência. $\mathrm{O}$ combate a esta realidade precisa começar na desconstrução de valores e concepções fundamentados em uma educação patriarcal e desigual, investigando e questionando os mecanismos reguladores que formam os sujeitos em nossa sociedade (BUTLER, 2018).

Todos os procedimentos da pesquisa foram claros e transparentes, respaldados pelas determinações do Conselho Nacional de Saúde.

\section{CONCLUSÃO}

Através deste estudo, podemos observar uma notável relação entre o desenvolvimento do transtorno de automutilação e a violência sexual sofrida principalmente por meninas, na favela da Pedreira, no Rio de Janeiro. A ausência de mecanismos e ambientes qualificados à atenderem a necessidade destes jovens de expressarem suas emoções e dores psíquicas, acaba por fomentar o desenvolvimento de tal comorbidade. A falta de assistência, o despreparo e inabilidade dos agentes públicos nestes locais de profunda carência econômica, contribui em demasia para que este ciclo de violência e de comportamentos autodestrutivos, se propague. A necessidade de repensarmos a forma como educamos em gênero se faz urgente, principalmente se levarmos em conta os crescentes índices de abusos contra mulheres, crianças e homossexuais noticiados diariamente em inúmeros veículos jornalísticos. Neste cenário, se faz indispensável o debate sobre a instauração de um modelo de escola multicultural, onde a educação em gênero seja abordada de modo diferenciado, promovendo igualdade e prevenindo a violência. As crianças de hoje serão os adultos do futuro, e cabe à escola, e demais instituições socializadoras, oportunizar que sua clientela experiencie a inclusão e o acolhimento das diferenças. Contudo, isso só será possível ao entendermos que esta batalha se concentra prioritariamente no campo ideológico. Cabendo-lhes reagir ao poder simbólico exercido por meio das relações sociais estabelecidas, através da desconstrução de paradigmas e ressignificação de crenças sociais. 
Promover saúde, nos outorga o dever de pensa-la holisticamente, e neste prisma, ponderarmos sobre os modelos de instituições socializadoras da atualidade, no intuito de viabilizarmos o desenvolvimento de uma sociedade mais justa e equânime.

É nosso desejo que este trabalho e outros tantos, possam ainda servir como mecanismos de convocação às demais ciências a refletirem acerca dos dispositivos utilizados para promoção de saúde, igualdade e prevenção de violência, com o intuito de adequá-los. Acreditamos na educação emancipatória e enxergamos a necessidade de repensarmos a escola e demais instituições, de modo a adequá-las às necessidades e demandas da contemporaneidade.

\section{REFERÊNCIAS}

AFONSO, M. L.; ABADE, F. L. Para reinventar as rodas: rodas de conversa em direitos humanos. Belo Horizonte: RECIMAM, 2008.

ALMEIDA FILHO, Naomar. O que é saúde? Rio de Janeiro: Editora Fiocruz, 2000.

ARAUJO, Liliana Aragão de; CRUZ, Maria Helena Santana. Discutindo a (In) Visibilidade do Trabalho de Peritos Médico-Legais a partir das Representações de Gênero e Violência Sexual. In: DIAS, Alfrancio Ferreira; CRUZ, Maria Helena Santana (Orgs.). Educação e Igualdade de Gênero. Jundiaí: Paco Editorial, 2015. p. 121140.

BEAUVOIR, Simone. O segundo sexo: A experiência vivida. 2.ed. São Paulo: Difusão Europeia do Livro, 1967.

BEAUVOIR, Simone. O segundo sexo: fatos e mitos. 4. ed. São Paulo: Difusão Europeia do Livro, 1970.

BOURDIEU, Pierre. A Dominação Masculina. 5. ed. Rio de Janeiro: Bertrand Brasil, 2017.

BOURDIEU, Pierre. O poder simbólico. Tradução Fernando Tomaz. Lisboa: Difel, 1989.

BUTLER, Judith. A vida psíquica do poder: teorias da sujeição. 1. ed. Belo Horizonte: Autêntica Editora, 2018.

CAVALCANTE, João Paulo Braga. Redes de depressão e cutting no cenário jovem alternativo: uma contribuição sociológica acerca da automutilação. 2014. Disponível em < http://historico.aps.pt/viii_congresso/ VIII_ACTAS/VIII_COM0743.pdf>. Acesso em: jul. 2018.

CANGUILHEM, Georges. O Normal e o Patológico. São Paulo: Forense Universitária, 1992.

FERREIRA, Geovana da Silva. Entre cortes e amarrações: considerações psicanalíticas sobre automutilação/ cutting na adolescência. 2016. Disponível em < $<$ http://bibliodigital.unijui.edu.br:8080/xmlui/bitstream/ handle/123456789/4289/Geovana\%20da\%20Silva\%20Ferreira.pdf?sequence=1>. Acesso em: jul. 2018.

GIUST, Jackeline Suzie. Automutilação: Características Clínicas e Comparação com pacientes com transtorno obsessivo-compulsivo. 2013. Disponível em < http://www.teses.usp.br/teses/disponiveis/5/5142/tde-03102013113540/pt-br.php>. Acesso em: jun. 2018.

GONÇALVES, Jaqueline Nascimento; SILVA, Elenita Pinheiro de Queiroz. Automutilação, Gênero, Sexualidade e Escola. In: RIBEIRO, Paula Regina Costa; MAGALHÃES, Joanalira Corpes (org.). Debates Contemporâneos sobre Educação para a Sexualidade. Rio Grande: Ed. da FURG, 2017. 
LOURO, Guacira Lopes. Gênero e sexualidade: pedagogias contemporâneas. Pro-Posições [online]. 2008, v.19, n.2, p.17-23. ISSN 1980-6248. Disponível em: <http://www.scielo.br/pdf/pp/v19n2/a03v19n2.pdf > . Acesso em 28-06-2018.

MÉLLO, R. P. et al. Construcionismo, práticas discursivas e possibilidades de pesquisa. Psicologia e Sociedade, v.19, n.3, p. 26-32, 2007.

MINAYO, Maria C. de S. (org.). Pesquisa social: teoria, método e criatividade. Rio de Janeiro: Vozes, 1993.

QUEIROZ, Paulo Pires de. Pensando a inclusão no processo de escolarização de alunos com deficiência. In: QUEIROZ, Paulo Pires de (org.). Ensino, Saúde e Inclusão: Olhares e Reflexões. Rio de Janeiro: Autografia, 2018.

SAMPAIO, Juliana; SANTOS, Gilney C.; AGOSTINI, Márcia; SALVADOR, Anarita de S. Limits and potentialities of the circles of conversation: analysis of an experience with young people in the backcountry of Pernambuco. Brazil. Interface (Botucatu). 2014; 18 Supl 2:1299-1312.

SCLIAR, Moacir. História do Conceito de Saúde. In: Physis, v. 17, nº 1, 2007. 